1 Role of guard-cell ABA in determining maximal stomatal aperture and prompt

2 vapor-pressure-deficit response

3 Adi Yaaran, Boaz Negin and Menachem Moshelion*

4 Faculty of Agriculture, Food and Environment, The Robert H. Smith Institute of Plant

5 Sciences and Genetics in Agriculture, The Hebrew University of Jerusalem, Rehovot

676100 , Israel.

$7 \quad *$ Author to whom correspondence should be addressed:

8 menachem.moshelion@mail.huji.ac.il; Tel.: 97289489781

9 adi.yaaran@mail.huji.ac.il

10 boaz.negin@mail.huji.ac.il

11 Date of submission: 13.11.2017

12 Number of figures: Figures 2-6 in color online-only, figures 1 and 7 in color in print

13 and 4 supplementary figures.

14 Word count: 6479 
15

\section{Role of guard-cell ABA in determining maximal stomatal aperture and prompt vapor-pressure-deficit response}

Running title: Guard-cell ABA and stomatal response to VPD

Highlight: Guard-cell ABA does not play a significant role in the immediate closure of stomata following an increase in the VPD, but is important for stomatal adaptation to ambient VPD.

\section{Abstract}

Abscisic acid (ABA) is known to be involved in stomatal closure. However, its role in stomatal response to rapid increases in the vapor pressure deficit (VPD) is unclear. To study this issue, we generated guard cell (GC)-specific ABA-insensitive Arabidopsis plants (GC-specific abil-1; GCabi). Under normal conditions, the stomatal conductance $\left(\mathrm{g}_{\mathrm{s}}\right)$ and apertures of GCabi plants were greater than those of control plants. This supports GC ABA role as limiting maximal stomatal aperture under nonstressful conditions. When there was a rapid increase in VPD $(0.15$ to $1 \mathrm{kPa})$, the $\mathrm{g}_{\mathrm{s}}$ and stomatal apertures of GCabi decreased in a manner similar that observed in the WT control, but different from that observed in WT plants treated with fusicoccin. Low VPD increased the size of the stomatal apertures of the WT, but not of GCabi. We conclude that GC ABA does not play a significant role in the initial, rapid stomatal closure that occurs in response to an increase in VPD, but is important for stomatal adaptation to ambient VPD. We propose a biphasic angiosperm VPD-sensing model that includes an initial passive-hydraulic, ABA-independent phase and a subsequent ABA-dependent steady-state phase in which stomatal behavior is optimized for ambient VPD conditions.

Key words: ABA, abi1-1, Guard cells, stomatal conductance, VPD, water balance.

Abbreviations: Abscisic acid (ABA), artificial xylem sap (AXS), guard cells (GC), relative water content (RWC), stomatal conductance $\left(g_{s}\right)$, vapor pressure deficit (VPD), water-use efficiency (WUE). 


\section{Introduction}

Stomata are microscopic pores that allow for controlled gas exchange between a plant and the atmosphere. In early-diverging vascular plants (i.e., ferns), stomatal control displays passive-hydraulic characteristics, such that small decreases in turgor result in rapid reductions in stomatal aperture, which are accompanied by a decrease in the rate of $\mathrm{CO}_{2}$ assimilation (Brodribb and McAdam, 2011). The emergence of an abscisic acid (ABA)-dependent stomatal regulation mechanism (approximately 360 million years ago) increased the flexibility of stomatal control (Brodribb and McAdam, 2011). This active-chemical mechanism initiates rapid signal transduction for the depolarization of guard cell (GC) membrane potential, decreased osmotic concentration, turgor loss and reduced stomatal aperture (Daszkowska-Golec and Szarejko, 2013; Munemasa et al., 2015).

Stomatal aperture is known to respond to differences between the vapor concentration within the leaf and the vapor concentration in the air. Mott (1991) showed that GC do not sense relative humidity $(\mathrm{RH})$ directly, but do respond to changes in the transpiration rate. The atmospheric vapor pressure deficit (VPD) serves as the driving force for transpiration, determining the rate at which water is lost from the leaf. An increase in the VPD (a greater difference in vapor concentrations) accelerates the loss of water from the leaf and initiates a reduction in stomatal aperture that prevents excessive water loss and protects the leaf from desiccation. Due to its important role in stomatal regulation, ABA has been considered as a possible key player in the mechanism by which the GC respond to changes in the VPD. McAdam and Brodribb (2016) recently showed that a reduction in leaf turgor can trigger ABA biosynthesis and that increased sensitivity of ABA synthesis to leaf turgor corresponds with a higher stomatal sensitivity to VPD, suggesting that the rapid biosynthesis of ABA in the leaf ( $10 \mathrm{~min})$ could be responsible for the angiosperms' stomatal VPD response (McAdam et al., 2015; Sussmilch et al., 2017). Moreover, an increase in GC ABA was measured 15 min after a drop in humidity (i.e., an increase in VPD; Waadt et al., 2014). Indeed, GC were shown to possess the entire ABA biosynthesis pathway (Bauer et al., 2013), which is sufficient for the stomatal response to low RH (Merilo et al., 2017). These last two findings support the hypothesis that GC self-synthesize ABA in response to an increase in VPD. However, other studies have suggested that ABA synthesis is not limited to 
the GC and that more intense ABA synthesis may take place elsewhere in the leaf (McAdam and Brodribb 2015). Mutants with impaired ABA metabolism (Xie et al., 2006; Okamoto et al., 2008; Merilo et al., 2013; Bauer et al., 2013; McAdam et al., 2015 Arabidopsis thaliana, Pisum sativum, Solanum lycopersicon) and signaling (Xie et al., 2006; Ache et al., 2010; Merilo et al., 2013; Arabidopsis thaliana) exhibited impaired stomatal responses to rapid changes in VPD. Buckley (2015) recently claimed that the increase in ABA content following an increase in the VPD can fill in a gap in the hydro-active feedback hypothesis, demonstrating how an ultimate mechanism (gene regulation) yields an intermediate signal and a proximate effect (stomatal closure).

There is also other evidence that is not congruent with the hypothesis that $\mathrm{ABA}$ is the main cause for the angiosperm stomatal VPD response. In a very recent study, Merilo et al. (2017) showed that a broad range of Arabidopsis ABA mutants (mostly ABAdeficient) exhibit a reduction in $g_{s}$ in response to an immediate increase in VPD that is similar or even more intense than that observed for the WT, raising anew the debate regarding the role of $\mathrm{ABA}$ in this process. This new evidence corresponds with the work of Assmann et al. (2000), which showed that ABA-deficient (abal) and ABAinsensitive (abi1-1, abi2-1) Arabidopsis mutants have a WT-like stomatal response to VPD, as well as the ABA-independent VPD stomatal closure pathway reported by Yoshida et al. (2006) and Merilo et al. (2017).

In order to better understand the role of GC ABA in angiosperms' responses to VPD, we generated, for the first time, GC-specific ABA-insensitive plants (GCabi Arabidopsis thaliana plants) using the abil-1 mutant gene under the control of a GCspecific promoter, resulting in dominant GC ABA insensitivity against a nonmanipulated background. We demonstrate that while $\mathrm{GC}$ ABA does play a role in adjusting stomatal aperture to the ambient VPD, it plays no role in sensing rapid changes in ambient VPD, which seems to decrease stomatal conductance and stomatal apertures via a mechanism that is not ABA-dependent.

\section{Materials and methods}

\subsection{Plant material}


103 Arabidopsis (Arabidopsis thaliana ecotype Colombia) lines that express GFP or abi11041 specifically in guard cells (GCGFP and GCabi lines, respectively) were generated 105 following transformation with GFP or abi1-1 expressed under the KST1 promoter 106 (Müller-Röber et al., 1995) using the floral-dip transformation method (Clough and 107 Bent, 1998). abil-1 is a gain-of-function mutation that also has dominant negative 108 features in terms of ABA-sensing (Koornneef et al., 1984; Gosti et al., 1999; Park et 109 al., 2009). Expression of abi1-1 results in ABA insensitivity despite the presence of the WT ABI and other redundant PP2Cs, even when the Arabidopsis gene is expressed in poplar (Populus x canescens [Ait.] Sm.; Arend et al., 2009) and tomato (Lycopersicon esculentum L.; Carrera and Prat, 1998). Independent transgenic lines for each construct were identified.

The Arabidopsis plants were grown in a growth chamber under short-day conditions (10 h light, light intensity of $\sim 150 \mu \mathrm{mol} \mathrm{m}-2 \mathrm{~s}-1$ ) at a controlled temperature of 20 $22^{\circ} \mathrm{C}$. Plants were exposed to $50 \%$ humidity $(\mathrm{VPD}=\sim 1.4 \mathrm{kPa}$ ) or covered with clear plastic lid to maintain $90 \%$ humidity (VPD $=\sim 0.2 \mathrm{kPa}$ ). All plants were grown in potting mix containing (w/w) $30 \%$ vermiculite, $30 \%$ peat, $20 \%$ tuff and $20 \%$ perlite (Shacham; Beit Haemek, Israel).

Cyrtomium falcatum ferns were obtained from the Givat Brenner Nursery (Israel) and were grown in a tropical greenhouse until they were transferred to the lysimeter system (described below).

\subsection{Generation of GCabi and GCGFP plants}

The abil-1 gene from an abil-1 plant (Landsberg ecotype) was cloned into the pDONR $^{\text {TM }} 221$ vector (Invitrogen; Waltham, MA USA) and the KST promoter (MüllerRöber et al., 1995) was cloned into pDONRP4P1r using Gateway BP reactions, and later recombined into a pK7M24GW two-fragment destination vector (Karimi et al., 2007) using a Gateway LR reaction, according to the manufacturer's instructions. The binary KST:abil-1 vector was transformed into agrobacterium by electroporation. The KST:GFP binary vector was constructed using the same method used to construct the KST:abil-1 binary vector, except that the abil-1 gene was replaced with the GFP (green fluorescent protein) gene. GCabi mutants were identified through the use of high- 
resolution melt analysis real-time PCR (Corbett Research Rotor-Gene 6000 cycler; Sydney, Australia) using forward (5TGGTCGGTTTGATCCTCAAT3) and reverse (5TAGCTATCTCCTCCGCCAAA3) primers. DNA of plants suspected to be transgenic was sequenced to confirm the presence of the abil-1 snip ( $\mathrm{G}$ to $\mathrm{A}$ at position 539) in the plant.

Comparison of four independent GCabi lines to the WT revealed that all of those GCabi lines had significantly higher stomatal conductance and larger stomatal apertures (Suppl. Fig. 1). All experiments were conducted using at least three randomly selected independent lines of homozygous T3 and T4 plants.

\subsection{Confocal microscopy imaging}

Images were acquired using the Olympus IX 81 inverted laser scanning confocal microscope (Fluoview 500; Olympus; Tokyo) equipped with a 488-nm argon ion laser and a $60 \times 1.0$ NA PlanApo water immersion objective. GFP was excited by $488-\mathrm{nm}$ light and the emission was collected using a BA 505-525 filter. A BA 660 IF emission filter was used to observe chlorophyll autofluorescence. Confocal optical sections were obtained at $0.5-\mu \mathrm{m}$ increments. The images were color-coded green for GFP and red for chlorophyll autofluorescence.

\subsection{Stomatal measurements}

Epidermal peels were soaked in 'closure' solutions, as described in Acharya et al. (2013), under a light intensity of $\sim 150 \mu \mathrm{mol} \mathrm{m}-2 \mathrm{~s}^{-1}$ one hour after dawn. After $2 \mathrm{~h}$, fusicoccin (Santa Cruz Biotechnology; Heidelberg, Germany) and ABA ((+)-cis, trans abscisic acid; Biosynth; Staad, Switzerland) were added to a final concentration of 10 $\mu \mathrm{M}$. Solvents (ethanol and DMSO) were added to the control treatment at the same concentration. Fusicoccin is a fungal toxin that stimulates stomatal opening by activating the plasma membrane ATPase even in the presence of supplemental ABA. The fusicoccin treatment served as a positive control (Suppl. Fig. 2).

The stomatal apertures (Figs. 5 and 6), stomatal densities and stomatal indices of the plants were determined using the rapid imprinting technique described by Geisler and 
161 Sack (2002). This approach allowed us to reliably score hundreds of stomata from each 162 treatment, each of which was sampled at the desired time. In brief, light-bodied 163 vinylpolysiloxane dental resin (Heraeus-Kulzer; Hananu, Germany) was attached to the 164 abaxial leaf side and then removed as soon as it had dried ( $1 \mathrm{~min})$. The resin epidermal 165 imprints were covered with nail polish, which was removed once it had dried. The nail166 polish imprints were mirror images of the resin imprints. The nail-polish imprints were 167 put onto microscope slides.

168 All stomata were photographed under a bright-field inverted microscope (1M7100; 169 Zeiss; Jena, Germany) on which a Hitachi HV-D30 CCD camera (Hitachi; Tokyo, 170 Japan) was mounted. Stomatal images were analyzed to determine aperture size using 171 the ImageJ software (http://rsb.info.nih.gov/ij/). A microscopic ruler (Olympus; Tokyo, 172 Japan) was used. Stomatal index was calculated as the number of stomata / (number of 173 stomata + number of epidermal cells).

\subsection{Measurements of whole-plant continuous canopy conductance}

175 Whole-plant continuous canopy conductance $\left(\mathrm{g}_{\mathrm{sc}}\right)$ was measured using an array of load176 cell lysimeters (Plantarray Gravimetric Prototype system, Plant-DiTech Ltd; Rehovot, 177 Israel), as described by Halperin et al. (2016). GCabi and WT Arabidopsis plants were 178 plated on kanamycin $(50 \mathrm{mg} \mathrm{mL}-1)$ selection medium or antibiotic-free medium, 179 respectively. After 3 weeks, the plantlets were transferred to 3.9-L pots (six plants per 180 pot), which were kept in the greenhouse. Pots were covered with plastic wrap and 181 gradually uncovered. C. falcatum ferns were planted directly into 3.9-L pots (one plant per pot).

183 The Arabidopsis plants were grown in a greenhouse under semi-controlled conditions of $26 / 12^{\circ} \mathrm{C}$ (day/night) and natural day length and light conditions in Rehovot, Israel during January and February of 2014. The ferns were grown in the greenhouse under a shade net and semi-controlled conditions of $27 / 18^{\circ} \mathrm{C}$ (day/night) and natural day length in Rehovot, Israel during May and June 2016. Daily measurements were conducted simultaneously for all of the plants in the array, so that all the plants were exposed to similar ambient conditions at each measurement point. Since no differences were observed between the three independent lines of GCabi used in previous experiments, 
191 only one line (GCabi9) was used in the lysimeter experiment, which allowed us to 192 increase the number of replicates of GCabi. Each pot was placed on a temperaturecompensated load cell. The soil surface surrounding each Arabidopsis plant was

194

195

196

197

198

199

200

201

202

203

204

205

206

207

208

209

210

211

212

213

214

215

216

217

218

219

220

221 covered to prevent evaporation. The pots holding ferns were not sealed, due to the large area from which fronds were initiated. The output (weight) of the load cells was monitored every $10 \mathrm{~s}$ and 3-min average values were logged in a data-logger for further analysis. Whole-plant transpiration was calculated as a numerical derivative of the loadcell output following a data-smoothing process. The daily water loss rate was normalized to the total plant weight to determine the transpiration rate. Continuous whole-canopy conductance was calculated by dividing the whole-plant transpiration rate by the VPD.

\subsection{Gas-exchange measurements}

Leaves of plants that were 7 to 9 weeks old were excised just before dawn and immediately immersed (petiole-deep) in artificial xylem sap (AXS; 3 mM KNO $3,1 \mathrm{mM}$ $\mathrm{Ca}\left(\mathrm{NO}_{3}\right)_{2}, 1 \mathrm{mM} \mathrm{MgSO} 4,3 \mathrm{mM} \mathrm{CaCl}, 0.25 \mathrm{mM} \mathrm{NaH}_{2} \mathrm{PO}_{4}, 90 \mu \mathrm{M}$ EDFC and a micromix of $0.0025 \mu \mathrm{M} \mathrm{CuSO}_{4} * 5 \mathrm{H}_{2} \mathrm{O}, 0.0025 \mu \mathrm{M} \mathrm{H}_{2} \mathrm{MoO}_{4}, 0.01 \mu \mathrm{M} \mathrm{MnSO}_{4}, 0.25$ $\left.\mu \mathrm{M} \mathrm{KCl}, 0.125 \mu \mathrm{M} \mathrm{H}_{3} \mathrm{BO}_{3} * 3 \mathrm{H}_{2} \mathrm{O}, 0.01 \mu \mathrm{M} \mathrm{ZnSO}_{4} * 7 \mathrm{H}_{2} \mathrm{O}\right)$. Cotton swabs were then used to smear leaves with $10 \mu \mathrm{M}$ fusicoccin (Santa Cruz Biotechnology) dissolved in ethanol and diluted with AXS, or with AXS containing the same concentration of ethanol. The leaves were then kept in the growth chamber for $1 \mathrm{~h}$ to allow the smeared material to dry. Then, the leaves were put into a sealed transparent plastic box, in which they were exposed to elevated humidity, up to $94 \%$ (VPD $=\sim 0.15 \mathrm{kPa}$ ), for $2 \mathrm{~h}$. From the beginning of the experiment, the boxes were kept in the lab under a light intensity of $\sim 150 \mu \mathrm{mol} \mathrm{m}-2 \mathrm{~s}-1$. The measurement data described below were collected using leaves from different boxes, in order to ensure a uniform, very humid starting point for all measurements

Gas-exchange measurements were taken using the LI-6400 portable gas-exchange system (LI-COR; Lincoln, NE, USA). In order to imprint leaves before and after the increase in VPD, pairs of leaves were prepared. At the beginning of each measurement, two leaves were taken from a box (VPD $=\sim 0.15 \mathrm{kPa}$ ), one leaf was immediately imprinted while the second leaf was placed in the LI-COR chamber for 20 min and then 
immediately imprinted. Measurements began $3 \mathrm{~min}$ after the leaf was placed in chamber, when the conditions in the chamber had. VPD was adjusted manually by adjusting the desiccant scrub flow during the $20 \mathrm{~min}(\mathrm{VPD}=0.93-1.07 \mathrm{kPa})$. The slope of the linear region of leaf response, from 9-17 min, was calculated. All measurements were taken between 10:00 and 15:00.

For the fern gas-exchange measurements, fronds were cut under water during the morning hours (8:00-8:30). From each frond, five leaflets (starting from the third leaflet from the top) were cut underwater and inserted into different Eppendorf tubes; the leaflets of each frond constituted a block. All treatments included AXS. Tubes that contained no DMSO were used to assess whether DMSO itself affected the gas exchange of $C$. falcatum (as was found in a previous experiment in which $0.4 \%$ DMSO was used). Blocks of the five $1.5-\mathrm{mL}$ tubes were then put into hermetically sealed transparent plastic boxes and left under lights for $1 \mathrm{~h}$. Following that hour, the boxes were opened for 5 min and measurement data was then collected.

\subsection{Dark treatments}

Two hours after dawn, well-watered whole plants were moved to darkness for $1 \mathrm{~h}$. After that hour, $\mathrm{g}_{\mathrm{s}}$ was measured using a leaf porometer (SC-1 Porometer; Decagon Devices, Inc., WA, USA). The plants were then moved back into the light $(\sim 150 \mu \mathrm{mol} \mathrm{m}-2 \mathrm{~s}-1)$ for an additional hour and $\mathrm{g}_{\mathrm{s}}$ was then measured once again.

\subsection{Stomatal conductance in drying soil}

Stomatal conductance of 10- to 13-week-old plants was measured using a leaf porometer (SC-1 Porometer) and volumetric water content was measured with a Prochek probe (Decagon Devices). All measurements were carried out between 10:00 and 13:00.

\subsection{Petiole-dip perfusion and leaf relative water content}

Leaves excised before dawn were immediately immersed (petioles only, as shown in Fig. 3) in AXS and kept at close to zero VPD for $2 \mathrm{~h}$ (in a humid, transparent box), 
249 followed by $2 \mathrm{~h}$ of exposure to ambient VPD $(\sim 0.7 \mathrm{kPa})$ under light $(125 \mu \mathrm{mol} \mathrm{s}-1 \mathrm{~m}-$

250 2). The duration and efficiency of the xylem-loading perfusion were confirmed in

251 separate leaves under the same experimental conditions by following the red dye

252 Safranin O (1\% w/v) through the leaf veins (Sigma Cat. No. S2255, 1\% w/w in AXS;

253 Fig. 3A).

254 Relative water content (RWC) was measured as described by Sade et al. (2015). In

255 short, leaf fresh weight (FW) was immediately recorded and leaves were then soaked

256 for $8 \mathrm{~h}$ in $5 \mathrm{mM} \mathrm{CaCl}_{2}$ at room temperature in the dark, after which the turgid weight

257 (TW) was recorded. Total dry weight (DW) was recorded after the leaves were dried

258 at $70^{\circ} \mathrm{C}$ to a constant weight. RWC was calculated as $(\mathrm{FW}-\mathrm{DW} / \mathrm{TW}-\mathrm{DW}) \times 100$.

\section{$259 \quad 2.10$. Statistical analysis}

260 Student's $t$-test was used for comparisons of two means and the Tukey-Kramer test was 261 used for comparisons of more than two means. Dunnett's test was used for comparisons 262 with the control. The Kruskall-Wallis non-parametric (one-way) test was used when the 263 variance was not homogeneous. All analyses were done using JMP software (SAS; 264 Cary, NC, USA).

\section{Results}

\subsection{Responses of GCabi stomata to ABA, drought and darkness}

267

268

After confirming the GC-specific expression of GFP under the KST promoter (GCGFP; Fig. 1A), we examined GCabi's stomatal responses to ABA and drought. Initially, we examined the stomatal apertures of WT and GCabi epidermal peels that had been soaked in $10 \mu \mathrm{M}$ ABA or $10 \mu \mathrm{M}$ fusicoccin (a fungal toxin that stimulates stomatal opening). As expected, ABA caused a significant reduction in the stomatal apertures of the WT. However it had no significant effect on the stomatal aperture of GCabi (Fig. 2A), indicating that the quantity-dependent dominancy of abil-1 (Wu et al., 2003) is maintained under the KST promotor. Moreover, under controlled conditions, the stomatal apertures of GCabi were significantly larger than those of the WT $(5.22+0.06$ and $4.66+0.08 \mu \mathrm{m}$, respectively). Fusicoccin led to the enlargement of stomatal 
apertures in both the WT and GCabi, resulting in similar wide-open apertures $(>5.7 \mu \mathrm{m}$; Fig. 2A) among both sets of plants.

The GCabi plants exhibited no significant reduction in their stomatal conductance $\left(\mathrm{g}_{\mathrm{s}}\right)$ in response to reductions in soil volumetric water content and their stomatal conductance was significantly higher than that of the WT plants throughout the soildrying treatment (Fig. 2B). The unimpaired responses of GCabi stomata to darkness and fusicoccin (Fig. 2C, A) indicate that these plants possess a functional stomatalmovement mechanism. The higher $\mathrm{g}_{\mathrm{s}}$ and water-loss rate of the GCabi plants, as compared to the WT, led to the lower leaf relative water content (RWC) observed in detached leaves from those plants, in which minimal hydraulic resistance had been expected (Fig. 3). However, that was not the case for the whole GCabi plants, in which bulk flow from the roots was not disturbed. Two hours after leaves were excised and immersed (petiole-deep) in artificial xylem sap, the RWC of GCabi leaves was significantly lower than that of the untreated WT leaves $(70.5 \%+3.5$ and $86.7 \%+1.1$, respectively) and not significantly different from that of the WT leaves that had been smeared with fusicoccin $(77.5 \%+1.1)$. This wilting may indicate that the high rate of water loss through stomata could not be compensated for by the leaf hydraulic conductance.

\subsection{GCabi plants exhibit a daily whole-plant canopy conductance pattern that is similar to that of the WT and different from that seen in the ferns}

$\mathrm{g}_{\mathrm{s}}$ is a dynamic parameter that changes over the course of the day in response to changes in environmental factors such as light and VPD. Since GCabi plants exhibit larger stomatal apertures and higher stomatal conductance, we were interested in monitoring their responses to daily changes in atmospheric conditions in the greenhouse. In order to measure the whole-plant canopy conductance $\left(\mathrm{g}_{\mathrm{sc}}\right)$ continuously among the GCabi plants and the control plants simultaneously, we used an array of lysimeters (see Materials and methods). Both WT and GCabi revealed similar patterns of $\mathrm{g}_{\mathrm{sc}}$ in response to the natural changes in the environmental conditions in the greenhouse, which included an increase in $g_{s c}$ during the early morning (when VPD is low and light levels are increasing), followed by a decline in $\mathrm{g}_{\mathrm{sc}}$ as VPD increased, down to a steadystate during late morning and the middle of the day (Fig. 4A, B). Despite the similar $\mathrm{g}_{\mathrm{sc}}$ 
308

309

310

311

312

patterns of GCabi and the WT, under well-irrigated conditions, GCabi exhibited significantly higher canopy conductance during most of the day (from 08:05 to 15:20; Fig. 4B).

The ferns' daily g gattern was different from that observed for Arabidopsis, including an increase in $\mathrm{g}_{\mathrm{sc}}$ during the early morning and a decrease down to the basal level as VPD increased during the early morning (Fig. 4C, D). Since fern insensitivity to ABA has been shown to be species- and growth condition-dependent (Hõrak et al., 2017), we confirmed the insensitivity of $C$. falcatum to ABA in work with petiole-fed ABA (Suppl. Fig. 3). The similar responses of the $\mathrm{g}_{\mathrm{sc}}$ of GCabi and the WT to changes in ambient conditions point to similar VPD-sensing in both types of plants or a stronger effect of some other signal such as light. Therefore, we decided to test the VPD-specific response of GC in a tightly controlled gas-exchange experiment.

\subsection{GCabi plants exhibit a WT-like stomatal response to an increase in VPD}

To study the role of ABA in the regulation of stomatal response to a sharp increase in VPD, we monitored changes in $\mathrm{g}_{\mathrm{s}}$ over a period of $20 \mathrm{~min}$, starting $3 \mathrm{~min}$ after leaves were transferred from low VPD conditions [0.15 kPa (high humidity)] to higher VPD conditions [1 kPa (lower humidity)], using the LI-COR 6400 chamber. Data were collected as soon as the chamber conditions stabilized (see Materials and methods). We also measured stomatal aperture before and after VPD was increased (Fig. 5). Fusicoccin treatment, which induces irreversible stomatal opening, was used as a positive control for non-sensitive open stomata. As expected, the sharp increase in VPD (from 0.15 to $1 \mathrm{kPa}$ ) resulted in a reduction in the $\mathrm{g}_{\mathrm{s}}$ of the WT (Fig. 5A), which was correlated with a reduction in the stomatal apertures of those leaves (Fig. 5C). Interestingly, WT leaves that had been treated with fusicoccin also exhibited reduced stomatal conductance (Fig. 5A), yet with a significantly more moderate slope than that observed for the untreated WT (Fig. 5B) and a smaller, yet significant reduction in stomatal aperture (Fig. 5C). As before, the $g_{s}$ and stomatal apertures of GCabi were significantly greater than those of the WT throughout the experiment (Fig. 5A, C). Nevertheless, the stomatal response patterns of GCabi to the jump in VPD, in terms of both $\mathrm{g}_{\mathrm{s}}$ and stomatal aperture, were similar to the response patterns observed for the WT. The $\mathrm{g}_{\mathrm{s}}$ graphs of the two sets of plants had the same slope $\left(0.33+0.013 \mathrm{mmol} \mathrm{m}^{-2}\right.$ 
$339 \mathrm{~s}^{-1} / \mathrm{min}$ ) and the two sets of plants also exhibited similar reductions in stomatal aperture

340 (48\% for the WT and $46 \%$ for GCabi; Fig. 5B).

\subsection{Responses of GCabi and the WT to different VPD conditions}

342 The higher $\mathrm{g}_{\mathrm{s}}$ of the GCabi plants can be explained by their larger stomatal apertures

343 (Figs. 2A, 5C) and their higher stomatal density. The fact that GCabi plants lose more 344 water through transpiration raises the possibility that lack of leaf turgor may lead to 345 their smaller-leaf phenotype (Fig. 6A) and, subsequently, to their higher stomatal 346 density (Fig. 6B). Therefore, we grew the plants under ambient (1.4 kPa) and low VPD $347 \quad(0.2 \mathrm{kPa}$, with a transparent plastic lid kept over the growth tray to reduce transpiration 348 and increase RWC). Indeed, the low VPD conditions restored the RWC of GCabi to the 349 level observed for the WT leaves. That is, WT plants were able to preserve relatively 350 high RWC under both high- and low-VPD conditions; whereas the RWC of GCabi 351 decreased under ambient VPD conditions (Fig. 6C). Nevertheless, despite the RWC 352 differences, GCabi leaf area did not change and remained smaller than that of the WT 353 under both high and low VPD conditions (Fig. 6A). The small size of the GCabi leaves 354 cannot fully explain GCabi's higher stomatal density under higher VPD conditions. 355 (WT stomata were 1.48 times larger; whereas GCabi stomata were 1.7 times denser). 356 Therefore, stomatal index (number of stomata per epidermal cell) was measured as well.

357 The GCabi stomatal index was higher than that of the WT under ambient conditions 358 and decreased to match the unchanged stomatal index of the WT under low-VPD 359 conditions (Fig. 6D). Interestingly, the total number of stomata per leaf for GCabi and 360 WT was similar under both VPD growing conditions (Fig. 6E). In addition, the long361 term, low-VPD conditions increased WT stomatal apertures to the level seen for GCabi. 362 In contrast, GCabi stomatal aperture remained constant under the two VPD conditions 363 (Fig. 6F).

\section{Discussion}

\subsection{ABA's role in regulating stomatal aperture under non-stressful conditions}

The fact that the GC-specific ABA-insensitive plants (GCabi) had significantly larger stomatal apertures and greater stomatal and canopy conductance than the WT under 
368

369

370

371

372

373

374

375

376

377

378

379

380

381

382

383

384

385

386

387

388

389

390

391

392

393

394

395

396

397

398

399

400

well-irrigated conditions (Figs. 2, 4B, 5AC, 6F) supports the findings of previous studies, which have suggested that ABA plays a housekeeping role in limiting maximal stomatal apertures under non-stressful conditions (Kelly et al., 2013; Pantin et al., 2013b; Merilo et al., 2017). Moreover, the fact that higher VPD caused a change in WT stomatal apertures, but not GCabi stomatal apertures (Fig. 6F) supports the theory that GC sensitivity to ABA plays a key role in that housekeeping role. The non-maximal aperture mediated by ABA has been hypothesized to play a role in one of the following optimization process: 1) improving plant water-use efficiency (WUE; Yoo et al., 2009); 2) coordinating transpiration with photosynthesis (Kelly et al., 2013); or 3) coordinating transpiration with vascular hydraulic limitations that may make the plant incapable of supporting the excessive transfer of water to transpiring leaves (Sack and Holbrook, 2006), leading to reduced leaf water potential (Shatil-Cohen et al., 2011; Pantin et al., 2013a). Lack of sufficient hydraulic conductivity can also explain the low RWC of the GCabi and WT + Fus detached leaves, as compared with the untreated WT (Fig. 3C), despite the fact that these leaves were submerged in solution and xylem-borne dye moved freely throughout each leaf (Fig. 3A, as well as Shatil-Cohen et al., 2011, 2012).

Our results emphasize the fact that this stomatal aperture-limiting role of ABA is related specifically to the GC, as opposed to being a byproduct of the effect of ABA on hydraulic signals [i.e., vascular radial conductance or mesophyll water permeability, as demonstrated by Shatil-Cohen et al. (2011) and Pantin et al. (2013a)]. Such a hydraulic effect of a non-stomatal ABA response could have been involved in previously reported observations of whole-plant ABA-mutant lines and lines in which ABA production was limited to the GC (Bauer et al., 2013; Merilo et al., 2017) or phloem (Merilo et al., 2017). To address that issue, we performed this work using a mutant in which the GC were the only cells insensitive to ABA. Indeed, Merilo et al. (2017) showed that the $\mathrm{g}_{\mathrm{s}}$ and hysteresis of an ABA-deficient mutant were correlated with leaf ABA levels; whereas an ABA-insensitive mutant (whole-plant mutant; mutant 112458) exhibited an altered response to change in VPD. That finding contrasts with the results of our work with a GC-specific ABA-insensitive mutant (which exhibited a pattern similar to that observed for the WT). As the main difference between the two ABA-insensitive plants is the sensing tissue ( $\mathrm{GC}$ in our experiment and the whole plant in the 112458 mutant), it may be that some internal-tissue response to ABA was involved in GCabi's response to VPD change, but not in that of the 112458 mutant, further emphasizing the 
401

402

403

404

405

406

407

408

409

410

411

412

413

414

415

416

417

418

419

420

421

422

423

424

425

426

427

428

429

430

431

importance of internal-tissue feedback for stomatal activity and the importance of GC ABA for determining maximal stomatal aperture.

\subsection{Stomata-VPD relations and ABA's role in the passive-hydraulic $g_{s}$ response}

Typically, the daily pattern of $\mathrm{g}_{\mathrm{s}}$ is strongly correlated with daily changes in VPD. This daily $g_{s}-$ VPD pattern is characterized by high $g_{s}$ in the early morning when VPD is low and a decrease in $\mathrm{g}_{\mathrm{s}}$ as VPD increases during morning hours, as the temperature rises and the relative humidity falls (Ullmann et al., 1985; Raschke and Resemann, 1986; Brodribb and Holbrook, 2004; Kelly et al., 2013; Halperin et al., 2016; Fig. 3A, C). Obviously, this daily $\mathrm{g}_{\mathrm{s}}-$ VPD pattern is influenced by seasonal conditions, for example, higher maximal aperture and a slower rate of decrease are observed under the lower VPD levels typical of a rainy season (Brodribb and Holbrook, 2004). The impact of lower-VPD conditions on maximal stomatal aperture was also detected among our WT plants grown under $0.2 \mathrm{kPa}$ VPD, which had stomatal apertures that were $65 \%$ larger than those of WT plants grown under a VPD of $1.4 \mathrm{kPa}$. In contrast, this phenomenon was not observed among the GCabi plants, whose stomatal apertures were wider and unaffected by the change in VPD (Fig. 6F). The fact that the daily $g_{s c}-$ VPD pattern of GCabi was similar to that of the WT, but with higher levels of $g_{s c}$ throughout the day (Fig. 4A, B), supports the claim that ABA plays a housekeeping role in limiting the potential size of stomatal apertures under non-stressful conditions, as well as its nonfunctioning in the passive hydraulic $\mathrm{g}_{\mathrm{s}}$ reduction (Assmann et al., 2000; Merilo et al., 2017). Measurement of the daily $\mathrm{g}_{\mathrm{sc}}-\mathrm{VPD}$ pattern of the ABA-insensitive fern $(C$. falcatum; Fig. 4C, D, Suppl. Fig. 3) revealed a similarity with the Arabidopsis morning $\mathrm{g}_{\mathrm{sc}}$ peak, which was followed by a decline (back to basal level) in $\mathrm{g}_{\mathrm{sc}}$ by late morning. It was previously suggested that the stomatal closure-response of ferns to an increase in VPD could be a passive hydraulic response that does not involve ABA (Brodribb and McAdam, 2011; McAdam and Brodribb, 2014, 2015). Specifically, the ferns' GC lose turgor as the VPD grows, resulting in stomatal closure that is not mediated by ABA. Conifers (which represent a phylogenetic midpoint between the fern and angiosperm clades) represent an intermediate stage in the development of ABA stomata regulation, in which ABA enhances stomatal closure under drought stress (Brodribb and McAdam, 2013), but is not involved in stomatal responses to VPD (McAdam and Brodribb, 2015). 
432 The Arabidopsis ABA-independent response to an increase in VPD was replicated in a

433 tightly controlled gas-exchange chamber, in which the patterns of stomatal aperture and $434 \mathrm{~g}_{\mathrm{s}}$ responses of GCabi leaves were similar to those observed for the WT (Fig. 4).

435 This ABA-independent response of GC to VPD may be due to the passive-hydraulic 436 response mechanism, which may be attributed to either ancestral regulation that has 437 remained significant in some angiosperm species, including Arabidopsis (McAdam and 438 Brodribb, 2015), or a mechanism that regulates the GC response to a new steady state 439 in bulk leaf turgor (i.e., the new balance between pressures of the GC and epidermal 440 cells; Glinka and Aviv, 1971; Zait et al., 2017). The second possibility could explain 441 GCabi's larger apertures under ambient conditions (operating close to turgor loss point; 442 Fig. 2), so that GC turgor dominates epidermal pressure, as in a "continuous wrong443 way response." Yet, GCabi stomatal aperture was unchanged when RWC increased 444 (i.e., higher turgor, low VPD), weakening that argument (Fig. 5B, F). In addition, 445 differences in the balance of pressures between the epidermis and GC are expected to 446 be reflected in stomatal-closure dynamics that differ from those observed for the WT 447 control, such as those seen for the fusicoccin-treated WT leaves, but not for GCabi (Fig. 448 5).

449 Alternatively, the ABA-independent response of GC to VPD could be due to a physical, 450 as yet unknown parameter that co-varies with transpiration, so that the GC sense 451 changes in the flux of water through the stomate (Mott, 1991; Assmann et al., 2000). 452 In that case, both the perception of changes in the transpiration rate and the mechanism 453 by which that signal would be transduced remain unclear. OST1, a protein kinase active 454 downstream of $\mathrm{ABA}$, might be involved in such an $\mathrm{ABA}$-independent response 455 (Yoshida et al., 2006; Merilo et al., 2017).

\subsection{ABA-independent and ABA-dependent responses to VPD}

In light of the evidence presented above, it seems that (at least in Arabidopsis) the 458 stomatal response to a sharp increase in VPD involves three elements: leaf hydraulic 459 status, an ABA-independent mechanism and an ABA-dependent mechanism. A 460 possible explanation that includes all three of these elements could be that ABA is not 461 the initial cause of stomata closure, but rather a consequence of that closure. According 
462

463

464

465

466

467

468

469

470

471

472

473

474

475

476

477

478

479

480

481

482

483

484

485

486

487

488

489

490

491

492

to the above rationale, we suggest that while ABA became more and more dominant in stomatal regulation over the course of evolution (providing vascular plants with greater plasticity and helping them to adapt to new environments; Brodribb and McAdam, 2011; McAdam and Brodribb, 2015; Negin and Moshelion, 2017), angiosperms did not entirely lose their passive hydraulic stomatal-response mechanism. Nevertheless, the (symplastic) isolation of the GC from epidermal cells in the leaves of angiosperms (Kong et al., 2012; Sager and Lee, 2014) limits that hydraulic response, as compared to the hydraulic response observed in ferns. This "hydraulic independency" allows for larger stomatal apertures, but also means that active turgor loss is required to reduce stomatal aperture beyond the initial hydraulic passive response. We hypothesized that the potential advantage of this combined strategy is the flexibility to have two modes of action: 1) high WUE with high stomatal conductance (i.e., enabling high $\mathrm{CO}_{2}$ intake) during low VPD periods and 2) the ability to keep stomata slightly open during periods of higher VPD, even at the price of lower WUE (risk-taking anisohydric behavior; Negin and Moshelion, 2017; Tardieu and Simonneau, 1998). In this hypothetical biphasic model, a passive hydraulic response triggers an active ABA-dependent response and $\mathrm{ABA}$ enables the optimal maximal $\mathrm{g}_{\mathrm{s}}$ for each phase, corresponding to ambient conditions (i.e., soil water content and VPD).

The main role of $\mathrm{ABA}$ in the evolution of the angiosperms may have been in the adjustment of stomatal opening, as opposed to the common understanding of ABA as the stomatal-closing phytohormone. Accordingly, we can also explain angiosperms' relative long phase of steady-state $\mathrm{g}_{\mathrm{s}}$ (GC of both WT and GCabi maintained some turgor) during late morning and midday (Ullmann et al., 1985; Raschke and Resemann, 1986; Brodribb and Holbrook, 2004; Kelly et al., 2013; Halperin et al., 2016; Fig. 4B) and the lag in the rate at which stomata open following a sharp increase in VPD, as compared to the rate at which they close (McAdam and Brodribb, 2015, 2016; Merilo et al., 2017).

\subsection{ABA's role in adaptation to ambient VPD}

The goal of growing plants under low VPD was to reduce their water loss and increase their RWC. In addition, this experiment uncovered some interesting long-term effects of VPD on stomatal development and the stomatal response to ABA. Low-VPD 
493

494

495

496

497

498

499

500

501

502

503

504

505

506

507

508

509

510

511

512

513

514

515

516

517

518

519

520

521

522

523

524

525

conditions increased the size of WT apertures, but did not affect the large stomatal apertures of the GCabi plants (Fig. 6F). This is in agreement with previous studies that have shown that VPD conditions (1 to 4 days of exposure) affect stomatal aperture (Fanourakis et al., 2011; Aliniaeifard et al., 2014; Carvalho et al., 2015), the quantity of leaf ABA (Rezaei Nejad and van Meeteren, 2008; Arve et al., 2013; Giday et al., 2014) and stomatal sensitivity to ABA (Rezaei Nejad and van Meeteren, 2008; Aliniaeifard and Van Meeteren, 2013; Pantin et al., 2013b; Arve et al., 2014; Giday et al., 2014), which is reversed by the application of ABA (Fanourakis et al., 2011; Aliniaeifard et al., 2014) or air movement (Carvalho et al., 2015) during the low-VPD period. Growing GCabi plants under constant low-VPD conditions did not increase their leaf area, despite the observed increase in their RWC (Fig. 6A, C). This suggests that lack of turgor (Fig. 3B, 6C) is not the main cause of the small size of GCabi leaves and that the higher stomatal density of GCabi (Fig. 6B) is at least partially due to developmental modification, as seen in their higher stomatal index (Fig. 6D). Expressing abil-1 under a GC-specific promoter was sufficient to increase stomatal density relative to that observed for abil-1 mutants (Tanaka et al., 2013). This explains why the $g_{s}$ of the GCabi leaves was higher than that of WT leaves that were treated with fusicoccin, despite their similar stomatal apertures (Fig. 5A, C). Moreover, the fact that the promoter used to construct the GCabi plants is GC-specific (Müller-Röber et al., 1995; Kelly et al., 2013; Sade et al., 2014; Fig. 1) and likely activated late in or even after differentiation suggests that ABA may have an indirect effect on stomatal proliferation through stomatal aperture and the transpiration rate (Lake and Woodward, 2008), in addition to the direct effect suggested by Tanaka et al. (2013). The greater stomatal density of GCabi was VPD-dependent and was reduced when those plants were grown under low-VPD conditions (Fig. 6B). This contrasts with the findings of previous studies, which suggested that low RH (high VPD; Tricker et al., 2012; Chater et al., 2014; Carvalho et al., 2015) and/or ABA (Tanaka et al., 2013) suppress stomatal proliferation. In our experiment, reducing the VPD increased the size of stomatal apertures (Fig. 6F) and, subsequently, WT g (Fanourakis et al., 2011; Arve et al., 2013; Aliniaeifard et al., 2014). In contrast, the stomatal apertures of GCabi, which were large to begin with, had lower $g_{s}$ under lower VPD conditions, which could annul the transduction of stress signals, reducing GCabi's stomatal density and stomatal index to WT levels. The long-term outcome of these conditions resulted in the developmental 
526

527

528

529

530

531

532

533

534

535

536

537

538

539

540

541

542

543

544

545

546

547

548

549

550

551

552

changes observed, possibly balancing the loss of water through stomata with stomatal proliferation (Chater et al., 2014).

\subsection{Conclusion}

In this study, we describe a biphasic GC response to $\mathrm{ABA}$. We demonstrate the importance of $\mathrm{GC} \mathrm{ABA}$ for restricting stomatal apertures under well-irrigated conditions, in contrast to its insignificance in the immediate GC response to changes in VPD. In addition, we demonstrate that GC-specific ABA plays an indirect role in stomatal proliferation.

We summarize this study with a daily VPD- g $_{s}$ response-curve hypothesis (Fig. 7). This dynamic response-curve hypothesis is based on the notion that stomatal aperture always reflects the sum of signals sensed by the $\mathrm{GC}$ (e.g., light, $\mathrm{CO}_{2}$ and $\mathrm{ABA}$ ). The VPD signal has a special dual effect as it is the physical force that drives transpiration and also serves as a (direct or indirect) closing signal. Hence, under the natural dynamic pattern of daily signals, a typical $g_{s}$ curve of a well-irrigated plant is expected to show the following pattern (as illustrated in Fig. 7): The first daylight initiates stomatal opening. At that point, a continum between the leaf substomatal cuvity and the atmosphere (i.e., VPD) is established (i.e., the opening of stomata initiates the soilplant-atmosphere continuum, which was blocked while the stomata were closed). At this early hour, VPD is at its lowest level and stomatal apertures are at their largest. As the temperature rises, VPD increases gradually, which leads to proportional water flux through the stomata that causes a passive hydraulic reduction in $\mathrm{g}_{\mathrm{s}}$. In addition, the passive hydraulic response triggers corresponding ABA synthesis within minutes (McAdam and Brodribb, 2016; Sussmilch et al., 2017). The amount of ABA produced and GC sensitivity to ABA restrict the size of stomatal apertures, to keep $\mathrm{g}_{\mathrm{s}}$, at a steadystate level that is appropriate for the prevailing ambient conditions.

Fig. S1. Stomatal aperture and $\mathrm{g}_{\mathrm{s}}$ of all GCabi lines is compare to WT.

Fig. S2. Fusicoccin inhibits the effect of ABA on stomatal aperture in the WT. 
554 Fig. S4. Photo of representative WT and GCabi Arabidopsis plants grown under 555 ambient and low VPD conditions.

556 Acknowledgments: We thank Prof. Sarah Assmann for her knowledgeable remarks 557 regarding the use of the abil-1 mutant gene and Prof. Dizza Bursztyn for her assistance 558 with the statistical analysis.

$559 \quad$ No competing interests declared

560 Funding: This research was supported by the Israel Science Foundations, ISF (grant 561 no. 878/16) and grant no. 2015100 from the United States-Israel Binational Science 562 Foundation, BSF. 
563 Figure 1. GCabi plants. Six-week-old WT (A) Colombia and (B) GCabi plants. (C)

564 A fluorescent image (488-nm excitation; 520-nm emission) of a leaf expressing GFP 565 under the KST promoter. (D) Sequence of KST:abi (GCabi) cDNA, the arrow points 566 to the $\mathrm{G} \rightarrow \mathrm{A}$ mutation. This figure is available in colour at $\underline{\text { JXB online. }}$.

567 Figure 2. GCabi exhibits no significant stomatal response to external ABA or 568 drought. (A) Stomatal apertures of WT (black bars) and GCabi (gray bars) epidermal 569 peels directly exposed to $10 \mu \mathrm{M}$ ABA or $10 \mu \mathrm{M}$ fusicoccin. Data points are averages 570 of at least three epidermal peels and represent a minimum of 160 stomata. (B) Stomatal 571 conductance of 10- to 13-week-old plants in response to continuous drought and (C) 572 stomatal conductance of 10- to 13-week-old plants exposed to light (125 $\mu$ mol s-1 m573 2) and then to $1 \mathrm{~h}$ darkness. Results are means \pm SE of at least 3 independent 574 experiments and 3 independent lines of GCabi (for B, $n=25-100$; for $\mathrm{C}, n=63$ ). (A, 575 C) Different letters indicate a significant difference according to the Tukey-Kramer test $576(P<0.05)$. (B) Different letters indicate a significant difference between treatments 577 within the same line and asterisks indicate a significant difference between lines 578 subjected to the same treatment, according to the Kruskall-Wallis non-parametric test $579 \quad(P<0.05)$.

580 Figure 3. Perfusion of detached leaves via their petioles (petiole dip). The low-

581 level stomatal regulation of GCabi leads to lower relative water content (RWC) in a 582 manner similar to that observed among WT leaves smeared with fusicoccin (FUS).

583 (A) The efficacy of the petiole-dip perfusion (see Materials and methods) was 584 confirmed by the fact that the xylem-borne dye spread throughout the leaf vasculature.

585 (B) WT leaves, WT leaves smeared with $10 \mu \mathrm{M}$ fusicoccin and GCabi leaves were 586 petiole-dipped in AXS without any safranin and (C) their relative water contents are 587 shown. Results are means + SE of 3 independent experiments $(n=15)$. Three 588 independent lines of GCabi plants were used. Different letters indicate a significant 589 difference (Tukey-Kramer test, $P<0.05$ ). This figure is available in color at $\underline{J X B}$ 590 online.

591 Figure 4. Daily pattern of whole-canopy stomatal conductance. GCabi and WT 592 Arabidopsis plants and ferns were grown under well-irrigated greenhouse conditions. 593 (A) Daily VPD (solid line) and light intensity (radiation, dashed line) for the 
594 Arabidopsis plants. (B) The whole-plant canopy stomatal conductance ( $\mathrm{g}_{\mathrm{sc}}$; g-1 h-1 unit 595 plant weight-1; plant weight, g) of GCabi (gray) and WT (black) Arabidopsis plants. 596 (C) Daily VPD (solid line) and light intensity (radiation, dashed line) for the ferns and 597 (D) the whole-plant canopy stomatal conductance of the ferns. The relatively high basal 598 level of fern $\mathrm{g}_{\mathrm{sc}}$ is related to the fact that the soil surrounding those plants was not 599 covered, due to the ferns' dense growth habit (see Materials and methods). Curves show 600 the means of 5 to 9 independent pots. Each pot included 6 plants; WT Arabidopsis 601 plants (black, $n=45$ ), GCabi plants (line GCabi9, gray, $n=25$ ) and ferns $(n=5)$. The 602 differences in ambient conditions (radiation and VPD) were due to the different 603 growing seasons (winter for Arabidopsis and summer for fern). Data are shown as 604 means \pm SE. The asterisk indicates a significant difference between GCabi and WT 605 according Student's $t$-test $(P<0.005)$.

606 607 608 609 610 611 612 613

Figure 5. GCabi plants exhibit a WT-like stomatal response to a rapid increase in VPD. (A) Changes in stomatal conductance over time in response to an increase in VPD from $0.15 \mathrm{kPa}$ to $1 \mathrm{kPa}$; WT (diamond), WT smeared with $10 \mu \mathrm{M}$ fusicoccin (square) and GCabi (triangle). Measurements began 3 min after a leaf was placed in the gasexchange chamber (see Material and methods). (B) The linear slope of $\mathrm{g}_{\mathrm{s}}$ (9 to $17 \mathrm{~min}$ ). (C) Bright-field microscopy images of stomatal imprints, measured on duplicate leaves exposed to a change in VPD at Minute 1 and Minute 24. The measurement data are also presented in bar graphs. The data shown in (A) and (B) are means of 20 leaves and at least 380 stomata for (C). Significant differences are indicated by letters (TukeyKramer test, $P<0.05)$ or by asterisks ( $t$-test, $P<0.01)$.

\section{Figure 6. Stomatal characteristics of GCabi and WT Arabidopsis plants in} response to ambient and low VPD conditions. Eight-week-old GCabi and WT plants were grown under ambient (1.4 kPa) or low (0.2 kPa) VPD conditions. (A) Leaf area; (B) stomatal density per $0.1 \mathrm{~mm}^{2}$ of leaf area; (C) leaf RWC; (D) stomatal index; (E) number of stomata per leaf and (F) stomatal aperture. Stomatal density, aperture and index were examined in 3 regions of 5 leaves from each treatment. For leaf area and RWC, $n=15$. Results are means \pm SE; different letters indicate a significant difference (Tukey-Kramer test, $P<0.05$ ). 
624 Figure 7. Our hypothetical biphasic stomatal VPD-sensing model. This model

625 suggests that under well-irrigated conditions (A) the stomatal conductance $\left(\mathrm{g}_{\mathrm{s}}\right)$ of the

626 WT (solid gray line) and GCabi (dashed gray line) generally increases rapidly,

627 beginning at the first light at dawn, when VPD is low (black line), and maximal $\mathrm{g}_{\mathrm{s}}$ (and

628 maximal stomatal aperture, SA, vertical red arrow) is reached during the morning, in 629 coordination with the sum of signals perceived by the GC, including the basal ABA

630 level. (B) The increasing VPD induces a higher rate of transpiration, which triggers a

631 reduction in $\mathrm{SA}$ and $\mathrm{g}_{\mathrm{s}}$ via a passive-hydraulic, $\mathrm{ABA}$-independent mechanism (blue

632 arrows). (C) The passive-hydraulic signal induces the synthesis of ABA (horizontal red

633 arrow), triggering the start of an ABA-dependent phase, which regulates the steady-

634 state $g_{s}$ and SA throughout the middle of the day and the afternoon (vertical red arrow).

635 This VPD-ABA synthesis feedback may serve as a regulatory mechanism that enables

636 the plant to optimize its SA under the prevailing VPD conditions. 
637

638

639

640

641

642

643

644

645

646

647

648

649

650

651

652

653

654

655

656

657

658

659

660

661

\section{References}

\section{Ache P, Bauer H, Kollist H, Al-Rasheid KAS, Lautner S, Hartung W, Hedrich R.} (2010). Stomatal action directly feeds back on leaf turgor: new insights into the regulation of the plant water status from non-invasive pressure probe measurements. The Plant Journal 62, 1072-1082.

Aliniaeifard S, Malcolm Matamoros P, van Meeteren U. (2014). Stomatal malfunctioning under low VPD conditions: induced by alterations in stomatal morphology and leaf anatomy or in the ABA signaling? Physiologia Plantarum 152, 688-699.

Aliniaeifard S, Van Meeteren U. (2013). Can prolonged exposure to low VPD disturb the ABA signalling in stomatal guard cells? Journal of Experimental Botany 64, 35513566.

Arend M, Schnitzler JP, Ehlting B, Hänsch R, Lange T, Rennenberg H, Himmelbach A, Grill E, Fromm J. (2009). Expression of the Arabidopsis mutant ABI1 gene alters abscisic acid sensitivity, stomatal development, and growth morphology in gray poplars. Plant Physiology 151, 2110-2119.

Arve LE, Carvalho DR, Olsen JE, Torre S. (2014). ABA induces $\mathrm{H}_{2} \mathrm{O}_{2}$ production in guard cells, but does not close the stomata on Vicia faba leaves developed at high air humidity. Plant Signaling \& Behavior 9, e29192.

Arve LE, Terfa MT, Gislerød HR, Olsen JE, Torre S. (2013). High relative air humidity and continuous light reduce stomata functionality by affecting the ABA regulation in rose leaves. Plant, Cell \& Environment 36, 382-392.

Assmann SM, Snyder J, Lee YJ. (2000). ABA-deficient (abal) and ABA-insensitive (abi1-1, abi2-1) mutants of Arabidopsis have a wild-type stomatal response to humidity. Plant, Cell \& Environment 23, 387-395. 
662 Bahrun A, Jensen CR, Asch F, Mogensen VO. (2002). Drought-induced changes in 663 xylem $\mathrm{pH}$, ionic composition, and ABA concentration act as early signals in field664 grown maize (Zea mays L.). Journal of Experimental Botany 53, 251-263.

665

666

667

668

669

670

671

672

673

674

675

676

677

678

679

680

681

682

683

684

Bauer H, Ache P, Lautner S, et al. (2013). The stomatal response to reduced relative humidity requires guard cell-autonomous ABA synthesis. Current Biology 23, 53-57.

Brodribb TJ, Holbrook NM. (2004). Diurnal depression of leaf hydraulic conductance in a tropical tree species. Plant, Cell \& Environment 27, 820-827.

Brodribb TJ, McAdam SAM. (2011). Passive origins of stomatal control in vascular plants. Science 331, 582-585.

Brodribb TJ, McAdam SAM. (2013). Abscisic acid mediates a divergence in the drought response of two conifers. Plant Physiology 162, 1370-1377.

Buckley TN. (2015). Stomatal responses to humidity: has the 'black box' finally been opened? Plant, Cell \& Environment 39, 482-484.

Carrera E, Prat S. (1998). Expression of the Arabidopsis abil-1 mutant allele inhibits proteinase inhibitor wound-induction in tomato. Plant Journal 15, 765-771.

\section{Carvalho DRA., Torre S, Kraniotis D, Almeida DPF, Heuvelink E, Carvalho SMP.} (2015). Elevated air movement enhances stomatal sensitivity to abscisic acid in leaves developed at high relative air humidity. Frontiers in Plant Science 6, 1-11.

Chater CCC, Oliver J, Casson S, Gray JE. (2014). Putting the brakes on: abscisic acid as a central environmental regulator of stomatal development. The New phytologist 202, 376-391.

Clough SJ, Bent AF. (1998). Floral dip: a simplified method for Agrobacteriummediated transformation of Arabidopsis thaliana. Plant Journal 16, 735-743. 
685 Daszkowska-Golec A, Szarejko I. (2013). Open or close the gate - stomata action 686 under the control of phytohormones in drought stress conditions. Frontiers in Plant 687 Science 4, 138.

688

689 690

Fanourakis D, Carvalho SMP, Almeida DPF, Heuvelink E. (2011). Avoiding high relative air humidity during critical stages of leaf ontogeny is decisive for stomatal functioning. Physiologia Plantarum 142, 274-286.

Geisler MJ, Sack FD. (2002). Variable timing of developmental progression in the stomatal pathway in Arabidopsis cotyledons. New Phytologist 153, 469-476.

Giday H, Fanourakis D, Kjaer KH, Fomsgaard IS, Ottosen CO. (2014). Threshold response of stomatal closing ability to leaf abscisic acid concentration during growth. Journal of Experimental Botany 65, 4361-4370.

Glinka Z, Aviv T. (1971). The effect of epidermal cell water potential on stomatal response to illumination of leaf discs of Vicia faba. Physiologia Plantarum 24, 476479.

Gosti F, Beaudoin N, Serizet C, Webb AAR, Vartanian N, Giraudat J. (1999). $\mathrm{ABI} 1$ protein phosphatase $2 \mathrm{C}$ is a negative regulator of abscisic acid signaling. The Plant Cell 11, 1897-1910.

Halperin O, Gebremedhin A, Wallach R, Moshelion M. (2016). High-throughput physiological phenotyping and screening system for the characterization of plantenvironment interactions. The Plant Journal 89, 839-850.

Hõrak H, Kollist H, Merilo E. (2017). Fern stomatal responses to $\mathrm{ABA}$ and $\mathrm{CO}_{2}$ depend on species and growth conditions. Plant Physiology 174, 672-679.

Karimi M, Bleys A, Vanderhaeghen R, Hilson P. (2007). Building blocks for plant gene assembly. Plant Physiology 145, 1183-1191. 
709

710

711

712

713

Kelly G, Moshelion M, David-Schwartz R, Halperin O, Wallach R, Attia Z, Belausov E, Granot D. (2013). Hexokinase mediates stomatal closure. Plant Journal 75, 977-988.

Kong D, Karve R, Willet A, Chen MK, Oden J, Shpak ED. (2012). Regulation of plasmodesmatal permeability and stomatal patterning by the glycosyltransferase-like protein KOBITO1. Plant Physiology 159, 156-168.

Koornneef M, Reuling G, Karssen CM. (1984). The isolation and characterization of abscisic acid-insensitive mutants of Arabidopsis thaliana. Physiologia Plantarum 61, $377-383$.

Lake JA., Woodward FI. (2008). Response of stomatal numbers to $\mathrm{CO}_{2}$ and humidity: control by transpiration rate and abscisic acid. New Phytologist 179, 397-404.

McAdam SAM, Brodribb TJ. (2014). Separating active and passive influences on stomatal control of transpiration. Plant Physiology 164, 1578-1586.

McAdam SAM, Brodribb TJ. (2015a). The evolution of mechanisms driving the stomatal response to vapor pressure deficit. Plant Physiology 167, 833-843.

McAdam SAM, Sussmilch FC, Brodribb TJ. (2015b). Stomatal responses to vapour pressure deficit are regulated by high speed gene expression in angiosperms. Plant, Cell \& Environment 39(3), 485-491.

McAdam SAM, Brodribb TJ. (2016). Linking turgor with ABA biosynthesis: implications for stomatal responses to vapour pressure deficit across land plants. Plant Physiology 171, 2008-2016.

Merilo E, Laanemets K, Hu H, et al. (2013). PYR/RCAR receptors contribute to ozone-, reduced air humidity-, darkness-, and $\mathrm{CO}_{2}$-induced stomatal regulation. Plant Physiology 162, 1652-1668. 
733

734

735

736

737

738

739

740

741

Merilo E, Yarmolinsky D, Jalakas P, Parik H, Tulva I, Rasulov B, Kilk K, Kollist H. (2017). Stomatal VPD response: there is more to the story than ABA. Plant Physiology 175, 00912.

Mott KA, Parkhurst DF (1991). Stomatal responses to humidity in air and helox. Plant, Cell \& Environment 14, 509-515.

\section{Müller-Röber B, Ellenberg J, Provart N, Willmitzer L, Busch H, Becker D,} Dietrich P, Hoth S, Hedrich R. (1995). Cloning and electrophysiological analysis of $\mathrm{KST1}$, an inward rectifying $\mathrm{K}^{+}$channel expressed in potato guard cells. The EMBO Journal 14, 2409-2416.

Munemasa S, Hauser F, Park J, Waadt R, Brandt B, Schroeder JI. (2015). Mechanisms of abscisic acid-mediated control of stomatal aperture. Current Opinion in Plant Biology 28, 154-162.

Negin B, Moshelion M. (2017). The advantages of functional phenotyping in pre-field screening for drought-tolerant crops. Functional Plant Biology 44, 107-118.

Okamoto M, Tanaka Y, Abrams SR, Kamiya Y, Seki M, Nambara E. (2008). High humidity induces abscisic acid 8'-hydroxylase in stomata and vasculature to regulate local and systemic abscisic acid responses in Arabidopsis. Plant Physiology 149, 825834.

Pantin F, Monnet F, Jannaud D. (2013a). The dual effect of abscisic acid on stomata. New Phytologist 197, 65-72.

Pantin F, Renaud J, Barbier F, et al. (2013b). Developmental priming of stomatal sensitivity to abscisic acid by leaf microclimate. Current Biology 23, 1805-1811.

Park SY, Fung P, Nishimura N, et al. (2009). Abscisic acid inhibits type 2C protein phosphatases via the PYR/PYL family of START proteins. Science 324, 1068-1071. 
757 Raschke K, Resemann A. (1986). The midday depression of $\mathrm{CO}_{2}$ assimilation in 758 leaves of Arbutus unedo L.: diurnal changes in photosynthetic capacity related to 759 changes in temperature and humidity. Planta 168, 546-558.

760 Rezaei Nejad A., van Meeteren U. (2008). Dynamics of adaptation of stomatal 761 behavior to moderate or high relative air humidity in Tradescantia virginiana. Journal 762 of Experimental Botany 59, 289-301.

763 764

Sack L, Holbrook NM. (2006). Leaf hydraulics. Annual Review of Plant Biology 57, $361-381$.

Sade N, Galkin E, Moshelion M. (2015). Measuring Arabidopsis, tomato and barley leaf relative water content (RWC). Bio-Protocol 5, e1451.

Sade N, Gallé A, Flexas J, Lerner S, Peleg G, Yaaran A, Moshelion M. (2014). Differential tissue-specific expression of NtAQP1 in Arabidopsis thaliana reveals a role for this protein in stomatal and mesophyll conductance of $\mathrm{CO}_{2}$ under standard and salt-stress conditions. Planta 239, 357-366.

Sager R, Lee JY. (2014). Plasmodesmata in integrated cell signalling: insights from development and environmental signals and stresses. Journal of Experimental Botany 65, 6337-6358.

Shatil-Cohen A, Attia Z, Moshelion M. (2011). Bundle-sheath cell regulation of xylem-mesophyll water transport via aquaporins under drought stress: a target of xylem-borne ABA? The Plant Journal 67, 72-80.

Shatil-cohen A, Moshelion M. (2012). The bundle sheath role as xylem-mesophyll barrier. Plant Signaling \& Behavior 7, 1088-1091.

Sussmilch FC, Brodribb TJ, McAdam SAM. (2017). Up-regulation of NCED3 and ABA biosynthesis occur within minutes of a decrease in leaf turgor but AHK1 is not required. Journal of Experimental Botany 68, 2913-2918. 
782

783

784

785

786

787

788

789

790

791

792

793

794

795

796

797

798

799

800

801

802

803

804

805

806

807

Tanaka Y, Nose T, Jikumaru Y, Kamiya Y. (2013). ABA inhibits entry into stomatallineage development in Arabidopsis leaves. Plant Journal 74, 448-457.

Tardieu F, Simonneau T. (1998). Variability among species of stomatal control under fluctuating soil water status and evaporative demand: modelling isohydric and anisohydric behaviours. Journal of Experimental Botany 49, 419-432.

Tricker PJ, Gibbings JG, Rodríguez López MC, Hadley P, Wilkinson MJ. (2012). Low relative humidity triggers RNA-directed de novo DNA methylation and suppression of genes controlling stomatal development. Journal of Experimental Botany 63, 3779-3814.

Ullmann I, Lange OL, Ziegler H, Ehleringer J, Schulze ED, Cowan IR. (1985). Diurnal courses of leaf conductance and transpiration of mistletoes and their hosts in central Australia. Oecologia 67, 577-587.

\section{Waadt R, Hitomi K, Nishimura N, Hitomi C, Adams SR, Getzoff ED, Schroeder} JI. (2014). FRET-based reporters for the direct visualization of abscisic acid concentration changes and distribution in Arabidopsis. eLife 3, e01739.

Wu Y, Sanchez JP, Lopez-Molina L, Himmelbach A, Grill E, Chua N. (2003). The abil-1 mutation blocks ABA signaling downstream of cADPR action. The Plant Journal 34, 307-315.

Xie X, Wang Y, Williamson L, et al. (2006). The identification of genes involved in the stomatal response to reduced atmospheric relative humidity. Current Biology 16, $882-887$.

Yoo CY, Pence HE, Hasegawa PM, Mickelbart MV. (2009). Regulation of transpiration to improve crop water use. Critical Reviews in Plant Sciences 28, 410431.

Yoshida R, Umezawa T, Mizoguchi T, Takahashi S, Takahashi F, Shinozaki K. (2006). The regulatory domain of SRK2E/OST1/SnRK2.6 interacts with ABI1 and 
bioRxiv preprint doi: https://doi.org/10.1101/218719; this version posted November 13, 2017. The copyright holder for this preprint (which was not certified by peer review) is the author/funder, who has granted bioRxiv a license to display the preprint in perpetuity. It is made available under aCC-BY-ND 4.0 International license.

808 integrates abscisic acid (ABA) and osmotic stress signals controlling stomatal closure 809 in Arabidopsis. Journal of Biological Chemistry 281, 5310-5318.

810 Zait Y, Shapira O, Schwartz A. (2017). The effect of blue light on stomatal 811 oscillations and leaf turgor pressure in banana leaves. Plant, Cell \& Environment 40, 812 $1143-1152$. 
bioRxiv preprint doi: https://doi.org/10.1101/218719; this version posted November 13,2017 . The copyright holder for this preprint (which was not certified by peer review) is the author/funder, who has granted bioRxiv a license to display the preprint in perpetuity. It is made available under aCC-BY-ND 4.0 International license.

\section{$813 \quad$ Figure 1}
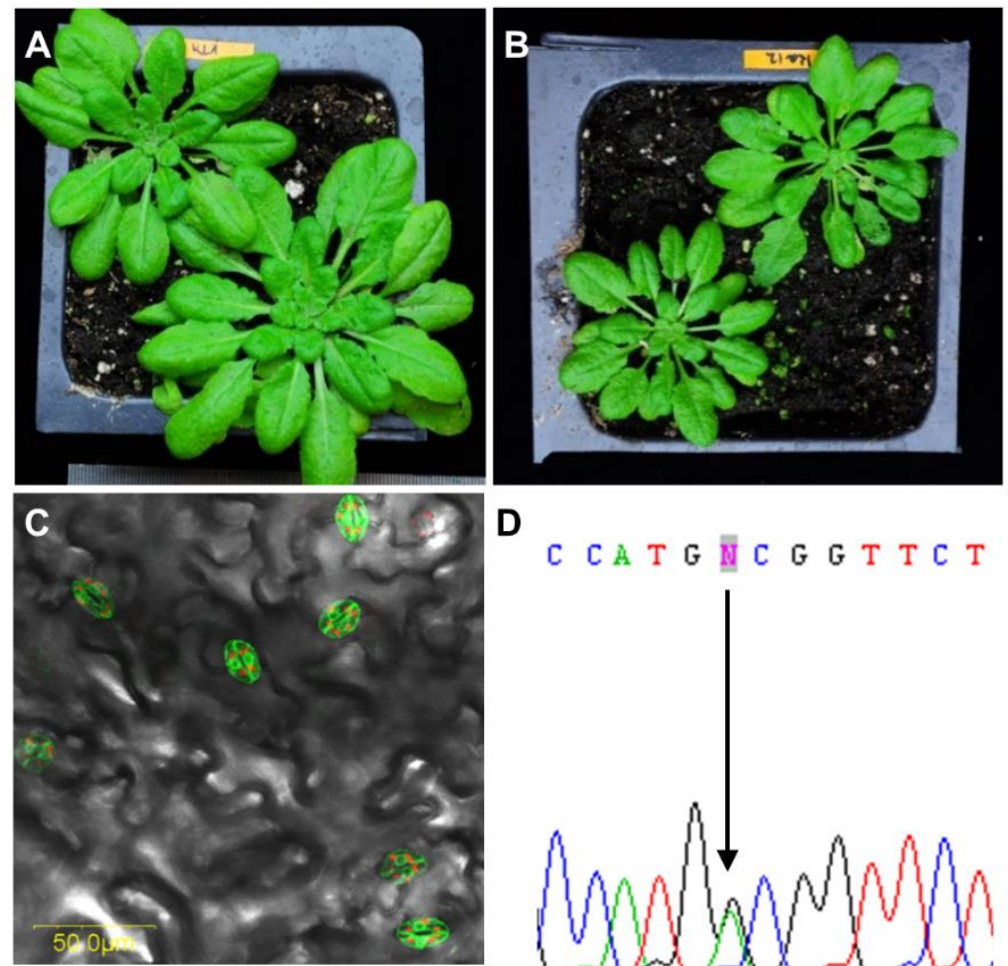

D

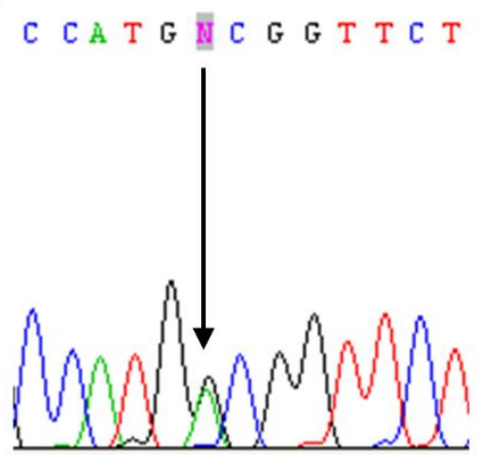


bioRxiv preprint doi: https://doi.org/10.1101/218719; this version posted November 13,2017 . The copyright holder for this preprint (which was not certified by peer review) is the author/funder, who has granted bioRxiv a license to display the preprint in perpetuity. It is made available under aCC-BY-ND 4.0 International license.

\section{$814 \quad$ Figure 2}
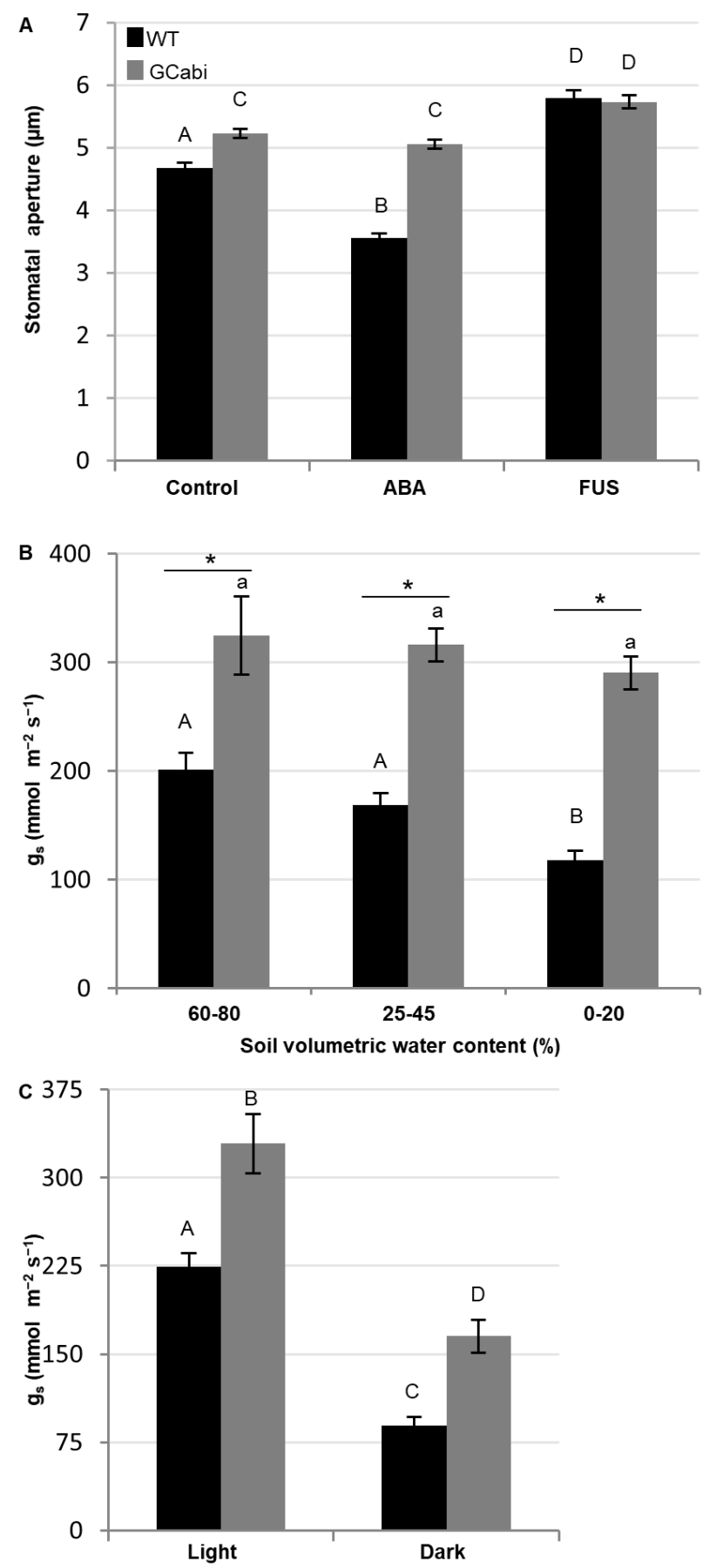
bioRxiv preprint doi: https://doi.org/10.1101/218719; this version posted November 13,2017 . The copyright holder for this preprint (which was not certified by peer review) is the author/funder, who has granted bioRxiv a license to display the preprint in perpetuity. It is made available under aCC-BY-ND 4.0 International license.

\section{$815 \quad$ Figure 3}
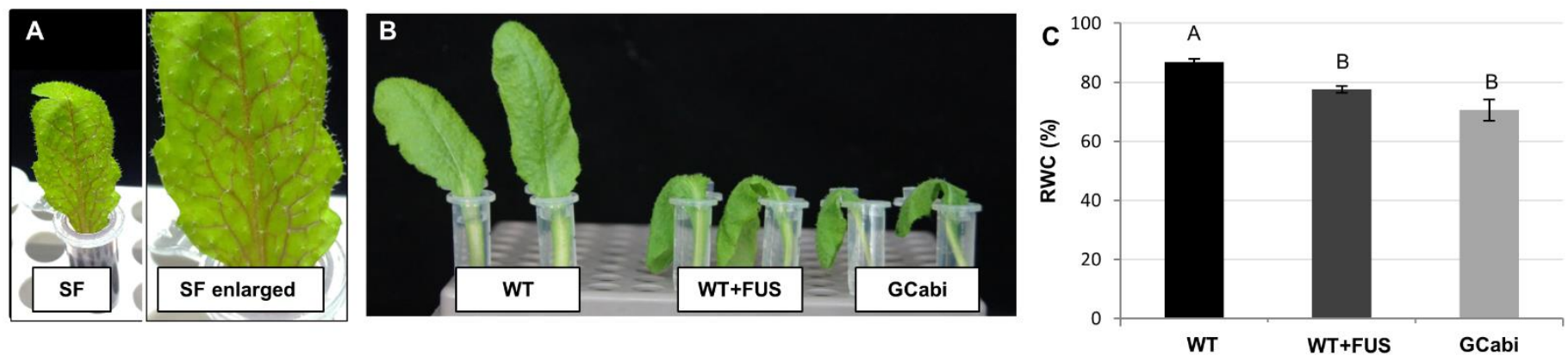
bioRxiv preprint doi: https://doi.org/10.1101/218719; this version posted November 13,2017 . The copyright holder for this preprint (which was not certified by peer review) is the author/funder, who has granted bioRxiv a license to display the preprint in perpetuity. It is made available under aCC-BY-ND 4.0 International license.

\section{$816 \quad$ Figure 4}

A
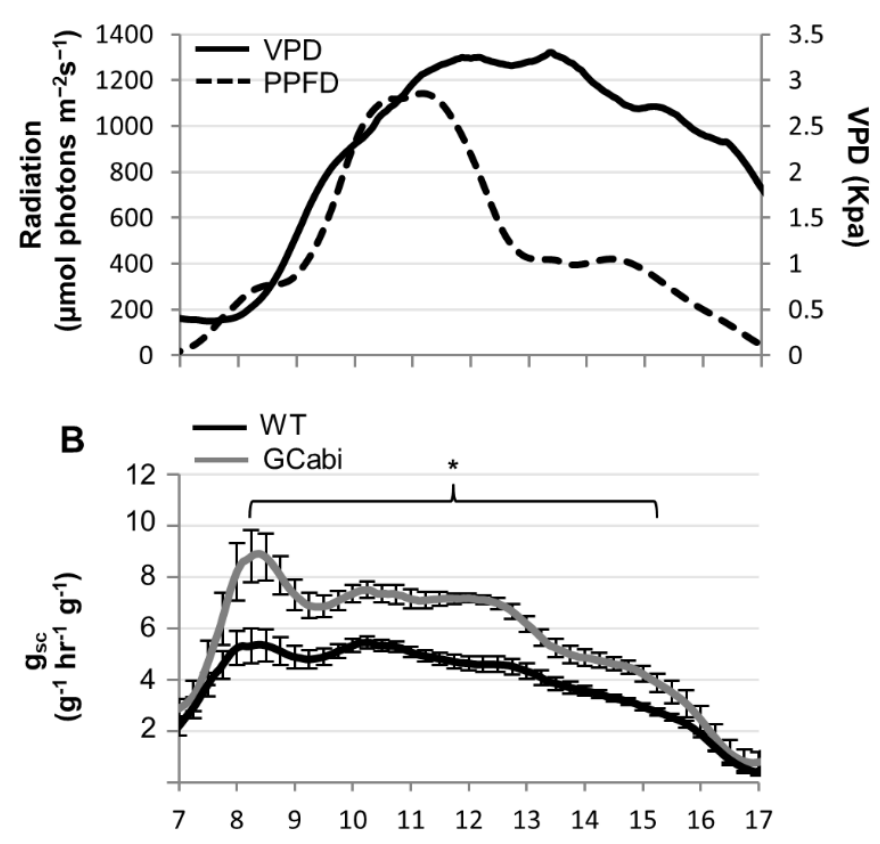

Time of day

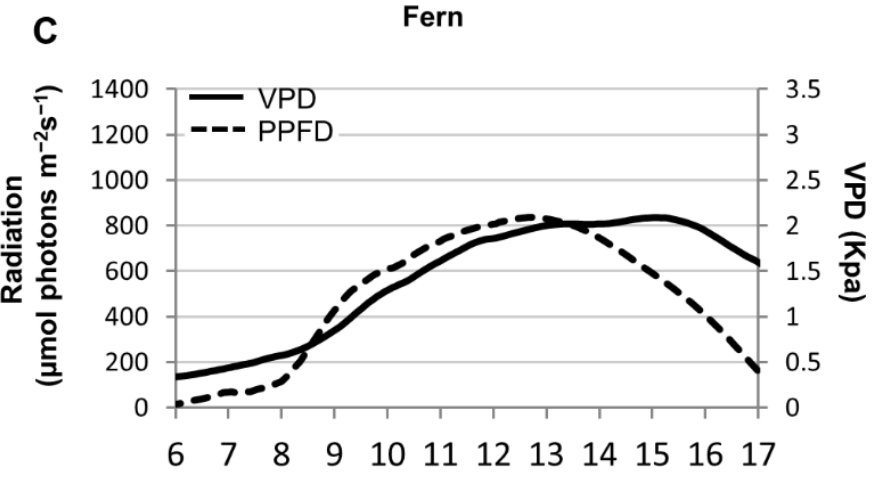

D

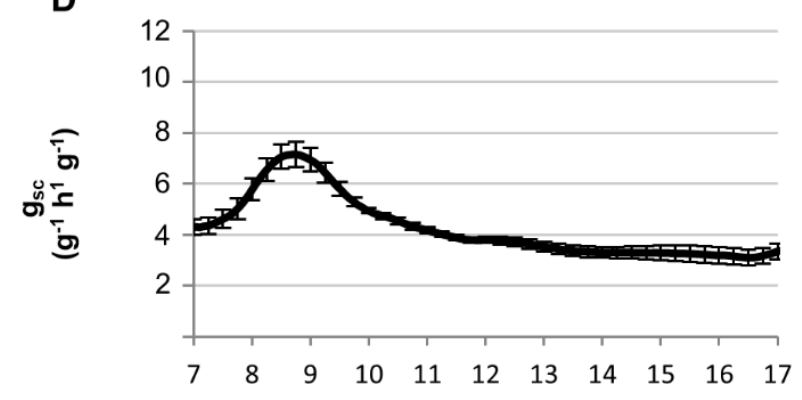

Time of day 
bioRxiv preprint doi: https://doi.org/10.1101/218719; this version posted November 13,2017 . The copyright holder for this preprint (which was not certified by peer review) is the author/funder, who has granted bioRxiv a license to display the preprint in perpetuity. It is made available under aCC-BY-ND 4.0 International license.
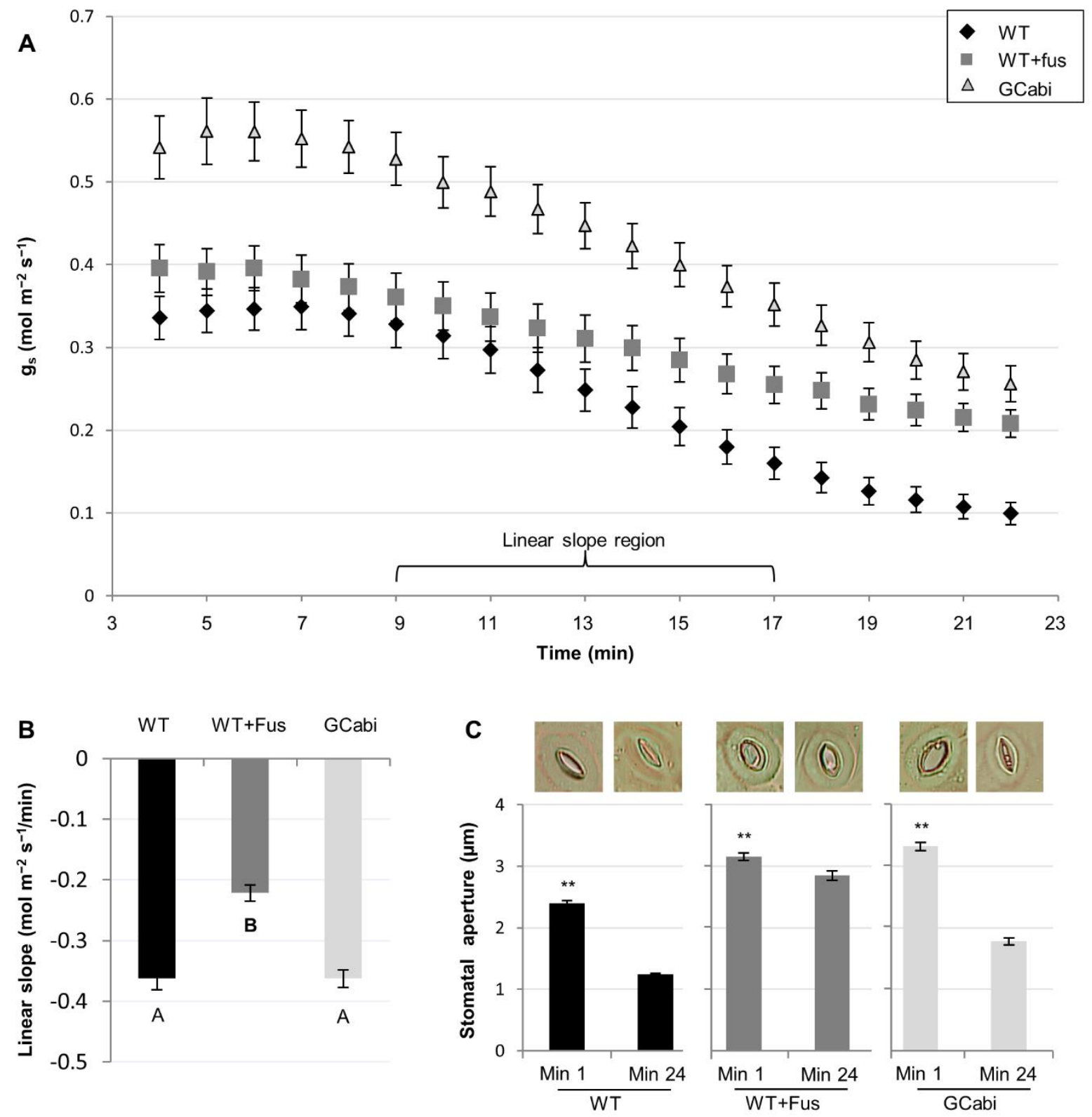
bioRxiv preprint doi: https://doi.org/10.1101/218719; this version posted November 13,2017 . The copyright holder for this preprint (which was not certified by peer review) is the author/funder, who has granted bioRxiv a license to display the preprint in perpetuity. It is made available under aCC-BY-ND 4.0 International license.

\section{$818 \quad \underline{\text { Figure } 6}$}

A

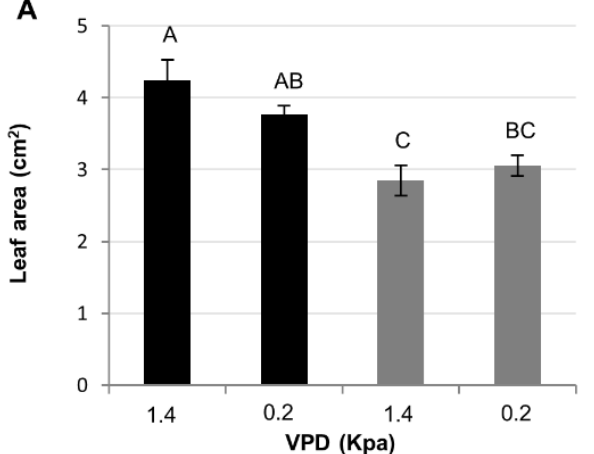

D

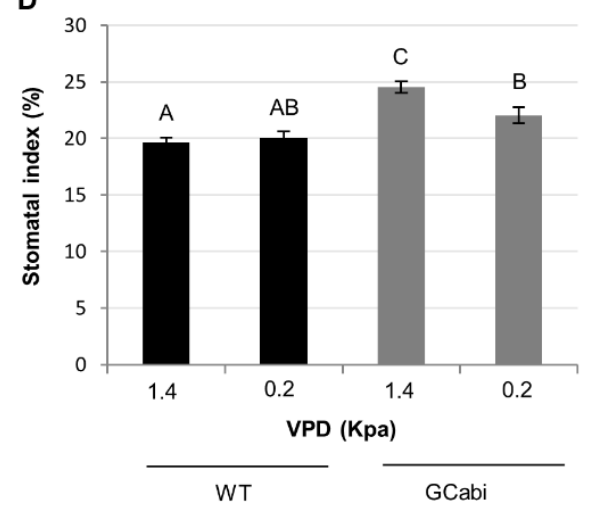

\section{B}
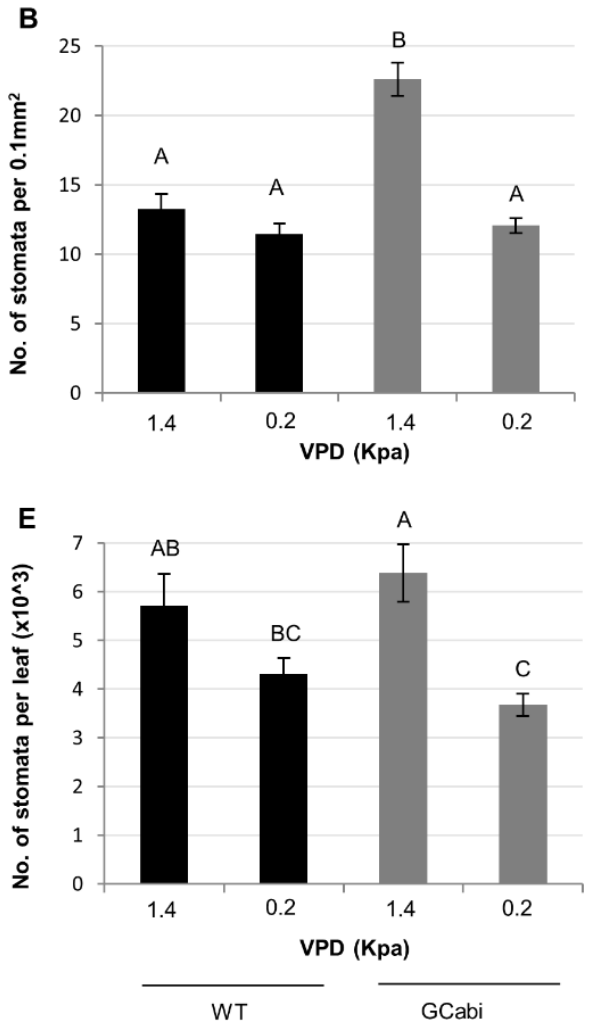

C

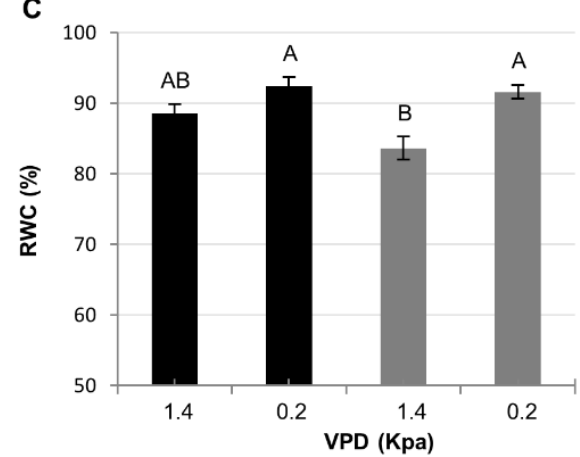

$\mathbf{F}$

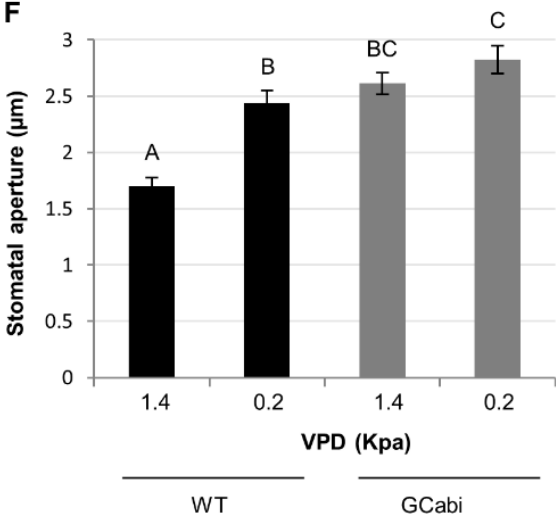


bioRxiv preprint doi: https://doi.org/10.1101/218719; this version posted November 13, 2017. The copyright holder for this preprint (which was not certified by peer review) is the author/funder, who has granted bioRxiv a license to display the preprint in perpetuity. It is made available under aCC-BY-ND 4.0 International license.

\section{$819 \quad$ Figure 7}

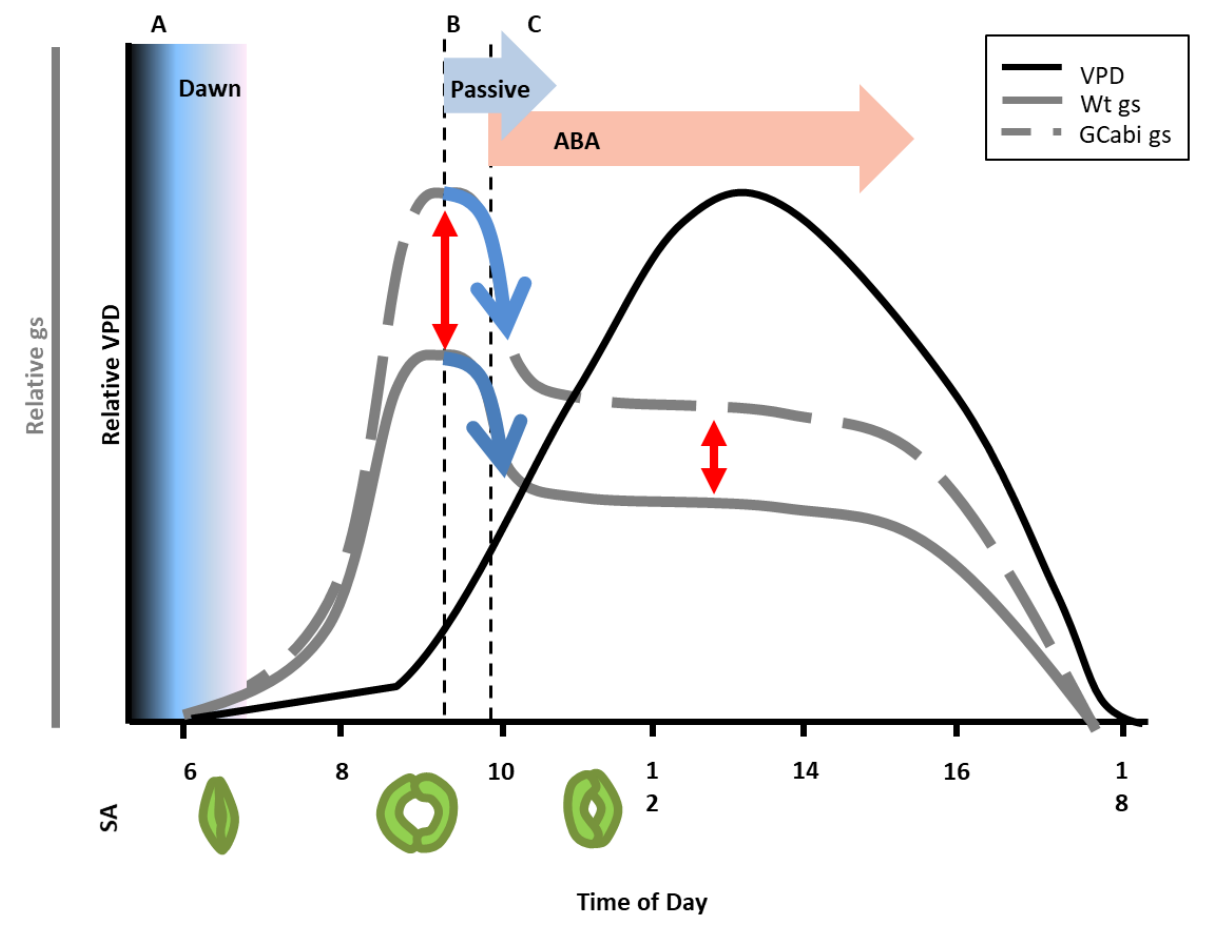

